Para citar este artículo: Arévalo-Martínez, R. I., \& Del Prado Flores, R. (2021). Comunicación digital de la Organización Internacional para las Migraciones: de la presencia a la colaboración. Anuario Electrónico de Estudios en Comunicación Social “Disertaciones”, 14(2), 1-25. https://doi.org/10.12804/revistas.urosario. edu.co/disertaciones/a.10389

\title{
COMUNICACIÓN DIGITAL DE LA ORGANIZACIÓN INTERNACIONAL PARA LAS MIGRACIONES: DE LA PRESENCIA A LA COLABORACIÓN
}

Digital Communication of the International Organization for Migration: From Presence to Collaboration

Comunicação digital da Organização Internacional para as Migrações: da presença à colaboração

Rebeca-Illiana Arévalo-Martínez, Universidad Anáhuac México (México)

rebeca.arevalo@anahuac.mx

Rogelio del Prado Flores, Universidad Anáhuac México (México)

rogelio.delprado2@anahuac.mx

Recibido: 15 de marzo de 2021

Aprobado: 26 de abril de 2021

Fecha de prepublicación: 1 de julio de 2021 


\section{DISERTACIONES}

AVANCES

\section{RESUMEN}

La comunicación digital de la Organización Internacional para las Migraciones (омм), organismo intergubernamental que promueve la migración humana, busca la cooperación internacional para encontrar soluciones y ofrece asistencia humanitaria a los migrantes. Esta investigación analizó la comunicación digital en 2019 y 2020 de la oım en Facebook y Twitter, a partir de la medición cuantitativa de la presencia, relevancia y reacción, en relación con el análisis de contenido de la interacción (proximidad, monitoreo, conexión y colaboración) respecto a los objetivos de la oım. Entre los principales hallazgos se encontró que la relevancia del contenido en 2020 en ambas redes sociales estuvo más enfocada en intereses de usuarios que en 2019; mientras que la interacción en 2020 fue mayor en Facebook que en Twitter. Sin embargo, no se observó un objetivo de la oı en ambas redes sociales que concentrara ni el mayor número de comentarios en 2020 ni de reacciones en 2019 y 2020. Los hallazgos permitieron identificar el impacto que tiene la comunicación digital de la oım entre sus seguidores y la falta de una verdadera colaboración que permita, más allá de informar, generar diálogo y crear una comunidad de apoyo al migrante.

Palabras clave: comunicación digital; migración; interacción.

\section{ABSTRACT}

The digital communication of the International Organization for Migration (Іом), an intergovernmental body that promotes human migration, seeks international cooperation to find solutions and offers humanitarian assistance to migrants. This research analyzed the digital communication in 2019 and 2020 of the Iom on Facebook and Twitter, based on the quantitative measurement of the presence, relevance and reaction, in relation to the content analysis of the interaction (proximity, monitoring, connection and collaboration) with respect to ıм's objectives. Among the main findings, it was found that the relevance of the content in 2020 in both social media was more focused on user interests than in 2019; while the interaction in 2020 was higher on Facebook than on Twitter. However, no Iom objective was observed in both social networks that concentrated neither the largest number of comments in 2020 nor reactions in 2019 and 2020. The findings made it possible to identify the level of impact that ım's digital communication has among its followers and the lack of true collaboration that allows, beyond informing, generating dialogue and creating a community of support for the migrant.

Keywords: Digital communication; migration; interaction.

\section{RESUMO}

A comunicação digital da Organização Internacional para as Migrações (oım), órgão intergovernamental que promove a migração humana, busca a cooperação internacional para encontrar soluções e oferece assistência humanitária aos migrantes. Esta pesquisa analisou a comunicação digital em 2019 e 2020 da oım no Facebook e Twitter, com base na medição quantitativa da presença, relevância e reação, em relação à análise de conteúdo da interação (proximidade, monitoramento, conexão e colaboração) com respeito aos objetivos da oım. Dentre os 


\section{DISERTACIONES}

AVANCES

Comunicación y controversias sociocientíficas en salud y medio ambiente

ISSN: $1856-9536$

Doi: https://doi.org/10.12804/revistas.urosario.edu.co/disertaciones/a.10389

Volumen 14, Número 2 / Julio-diciembre 2021

Versión PDF para imprimir desde

http://revistas.urosario.edu.co/index.php/disertaciones

principais achados, constatou-se que a relevância do conteúdo em 2020 nas duas redes sociais estava mais voltada para os interesses do usuário do que em 2019; enquanto a interação em 2020 foi maior no Facebook do que no Twitter; No entanto, nenhum objetivo do oım foi observado em ambas as redes sociais que não concentraram o maior número de comentários em 2020 nem de reações em 2019 e 2020. Os resultados permitiram identificar o nível de impacto que a comunicação digital do oı tem entre seus seguidores e os falta de uma verdadeira colaboração que permita, além de informar, gerar diálogo e criar uma comunidade de apoio ao migrante.

Palavras-chave: comunicação digital; migração; interação.

\section{Introducción}

La Organización Internacional para las Migraciones (омм) es un organismo intergubernamental que se enfoca en la promoción de la migración humana, la generación de lineamientos de impacto social y la búsqueda de la cooperación internacional para encontrar soluciones y ofrecer asistencia humanitaria a los migrantes. En el presente artículo se presentan los resultados de la investigación cuyo objetivo fue analizar la comunicación digital en 2019 y 2020 de la oım en Facebook y Twitter, a partir de la medición de las categorías de presencia, relevancia e interacción en estas redes sociales, así como de la categorización del contenido.

En el artículo se presenta una revisión de los principales aspectos teóricos y la situación actual de la migración, además de un análisis sobre la participación de los organismos internacionales y el estado de la cuestión. La investigación empírica revisa el contenido que publica la oı en redes sociales en apoyo a sus objetivos, así como la interacción que genera con sus usuarios. Al final del artículo se presentan algunas pautas sugeridas para que la orm, junto con otros organismos y actores sociales, aproveche de mejor manera estos canales de comunicación para el logro de sus objetivos y el bien común.

\section{Marco conceptual}

\section{Migración: conceptos y situación actual}

Existen varias aristas sobre el fenómeno migratorio; sin embargo, es un piso común considerar que los migrantes son "toda persona que se traslada fuera de su lugar de residencia habitual, ya sea dentro de un país o a través de una frontera internacional, de manera temporal o permanente, y por diversas razones" (омм, 2019c, párr. 1). En este sentido, se considera migrante quien se encuentra fuera de su residencia habitual "independientemente de: 1) su situación jurídica; 2) el carácter voluntario o involuntario del desplazamiento; 3) las causas del desplazamiento; o 4) la duración de su estancia" (Naciones Unidas, s. f., párr. 4). 


\section{DISERTACIONES}

AVANCES

Comunicación y controversias sociocientificas en salud y medio ambiente

ISSN: 1856-9536

Doi: https://doi.org/10.12804/revistas.urosario.edu.co/disertaciones/a.10389

Volumen 14, Número 2 / Julio-diciembre 2021

Versión PDF para imprimir desde

http://revistas.urosario.edu.co/index.php/disertaciones

Los diferentes procesos de globalización han repercutido en las migraciones internacionales, dado que cada vez más países se ven afectados por procesos migratorios y, a la vez, ello ha incrementado los flujos migratorios. Cada día, una mayor diversidad de migrantes se reciben en distintos países, lo que influye en la diferenciación cultural, el aumento de la feminización, la aceleración y politización de la migración (Castles \& Miller, 2004); así como en la vida misma de la localidad, de la región e incluso de todo el país. En 2017 se contabilizaron 258 millones de migrantes, el 3,4\% de la población mundial, de los cuales 68 millones de personas fueron desplazadas por la fuerza (25 millones de refugiados, 3 millones de solicitantes de asilo y más de 40 millones de desplazados internos) (Naciones Unidas, s. f.).

Los migrantes se enfrentan a dar un resignificado al espacio del hogar, en términos emocionales, relacionales, socioculturales y políticos, como parte de las consecuencias de la adaptación cultural (Kinefuchi, 2010). Por su parte, en el país receptor se hace necesaria la solidaridad, que se puede entender como las acciones que lleva a cabo un individuo y acepta su responsabilidad moral individual para alcanzar y satisfacer metas comunes (García \& Galvis, 2019). En este sentido, la solidaridad pone en el mismo nivel de prioridad e importancia el bien propio que el bien común. En otro punto, la confianza que se puede generar a partir de la comunicación social étnica se traduce en una interacción coétnica durante procesos de adaptación intrarregional (Sánchez et al., 2018); sin embargo, la integración no es homogénea y no es racionalmente ordenada. En este sentido, pese al apoyo que puede significar el recibir mensajes adaptativos dentro de los medios de comunicación, los migrantes experimentan discriminación laboral, de lenguaje y de identidad continental (Ju \& Sandel, 2019).

\section{Organismos o instancias internacionales y la migración}

La oı fue creada en 1951 y es "la principal organización intergubernamental en el ámbito de la migración y trabaja en estrecha colaboración con asociados gubernamentales, intergubernamentales y no gubernamentales" (Naciones Unidas, s.f., párr. 7). La oıм no forma parte del sistema de la Organización de las Naciones Unidas; es un organismo operativo logístico que "trabaja con los gobiernos y la sociedad civil para promover la comprensión sobre las cuestiones migratorias, alentar el desarrollo socioeconómico a través de la migración y velar por la dignidad humana y el bienestar de los migrantes" (оıм, 2019b, párr. 5). Sin embargo en 2016, la oıм llegó a un acuerdo con las Naciones Unidas y se convirtió en agencia especializada de la organización (Naciones Unidas, s. f.).

Cuenta con 173 Estados miembros y con 8 Estados observadores y tiene como objetivo: "promover la cooperación internacional sobre cuestiones migratorias; ayudar a encontrar soluciones prácticas a los problemas migratorios, y ofrecer asistencia humanitaria a los migrantes que lo necesitan, ya se trate de refugiados, de personas desplazadas o desarraigadas" (Naciones Unidas, s. f., párr. 7). La oıм (2019a) trabaja con sus socios de la comunidad internacional para:

- Ayudar a encarar los crecientes desafíos que plantea la gestión de la migración a nivel operativo.

- Fomentar la comprensión de las cuestiones migratorias.

- Alentar el desarrollo social y económico a través de la migración.

- Velar por el respeto de la dignidad humana y el bienestar de los migrantes (párr. 3). 


\section{DISERTACIONES}

AVANCES

Comunicación y controversias sociocientificas en salud y medio ambiente

ISSN: 1856-9536

Doi: https://doi.org/10.12804/revistas.urosario.edu.co/disertaciones/a.10389

Volumen 14, Número 2 / Julio-diciembre 2021

Versión PDF para imprimir desde

http://revistas.urosario.edu.co/index.php/disertaciones

Desde el año 2000 sucedió que, en general, los organismos internacionales volvieron su mirada al fenómeno de la migración y el desarrollo de los Estados. Particularmente, el Banco Mundial revaloró las remesas (de manera no neutral) y emitió una serie de recomendaciones sobre la migración a los Estados, al sector privado y a los propios migrantes (Pécoud, 2018). A partir de esta situación surgió un discurso internacional sobre la migración que propuso una visión integral de los problemas y las soluciones, así como la forma de encarar los retos con base en la cooperación entre los gobiernos y los organismos internacionales (Pécoud, 2018). Es decir, desde esta mirada financiera mundial, se marcó una narrativa preponderante de la migración, sus implicaciones, sus principales preocupaciones de los Estados receptores y las situaciones o condiciones que se debían vigilar y atender a este respecto. La migración ha llevado a que la sociedad esté más entrelazada que nunca, es decir, la posibilidad de que un Estado nación de manera egoísta subsista y se desarrolle en solitario es ya una utopía; por ello, la inclusión de los migrantes en la vida del país receptor es una necesidad prioritaria en la realidad que se vive actualmente (Sánchez et al., 2018).

\section{Estado de la cuestión}

Bajo el escenario del año 2020, según datos de la Comisión Económica para América Latina y el Caribe (Cepal, 2020), más de 40 millones de personas han tenido la necesidad de migrar de sus países de origen. Se trata de una movilidad intrarregional que ha aumentado por crisis sociales como la venezolana, el nuevo patrón que avanza desde Haití hacia América del Sur y las diversas vulnerabilidades relacionadas con la ruta que comprende Centroamérica, México y Estados Unidos. Para la Cepal (2020), la pandemia por covid-19 ha hecho aún más patente la dicotonomía entre modelos de desarrollo. Ante las crisis sociales que enfrenta la región, por un lado, está la estrategia dominante que se basa en la exclusión y la desigualdad; por otro, se encuentra la contribución del trabajo migrante que es flexible pero sumamente desprotegido y que paradójicamente tiene el potencial para facilitar la reactivación económica pospandemia. Gracias al trabajo de los migrantes se mantiene el desarrollo agrícola en tiempos de pandemia en el mundo entero; se trata de una contribución vital para garantizar el suministro de alimentos (FAO, 2020). La FAO (2020) señala que los migrantes desempeñan el trabajo en el marco de acuerdos ocasionales e informales por lo que son más susceptibles a la explotación laboral. La vida cotidiana de una persona en situación de migrante está caracterizada por la pobreza, por la inseguridad alimentaria y por carencias en materia de salud y protección social (Organización de las Naciones Unidas para la Alimentación y la Agricultura [FAo], 2020); sin embargo, por la gravedad de la crisis sanitaria, las personas en situación de migración se ven restringidas en el acceso a servicios básicos, y las medidas de distanciamiento físico están influyendo en los servicios que los gobiernos y las empresas prestan a los migrantes, como la entrega de alimentos y medicamentos a los más vulnerables (FAO, 2020).

La pandemia de la enfermedad por covid-19 se enmarca en un escenario migratorio que ya venía mostrando rasgos de involuntariedad y de una creciente movilidad intrarregional ya mencionada. La o (2020), la Cepal (2020), entre otros organismos, han alertado desde los primeros meses del inicio de la pandemia sobre la creciente estigmatización a los migrantes a razón de la enfermedad de la covid-19, que ha provocado el aumento de los actos discriminatorios. Esta intensificación tiene varias causas: las principales son la desinfodemia y la politización de la migración (Unesco, 2020). Sobre la desinfondemia vinculada a los migrantes durante la pandemia, la oı establece un brote paralelo de información falsa, "se ha perdido la prudencia en la información y se ha caído en la confusión durante esta crisis de salud pública” (2020, p. 3); mientras que la politización se ve 


\section{DISERTACIONES}

AVANCES

Comunicación y controversias sociocientificas en salud y medio ambiente

ISSN: 1856-9536

Doi: https://doi.org/10.12804/revistas.urosario.edu.co/disertaciones/a.10389

Volumen 14, Número 2 / Julio-diciembre 2021

Versión PDF para imprimir desde

http://revistas.urosario.edu.co/index.php/disertaciones

reflejada por las acciones beligerantes de los grupos antimigrantes, que difunden teorías conspiratorias sobre el origen del virus, "apuntan a la migración y a los migrantes como la causa del brote de la covid-19" (oım, 2020, p. 2). Para la oıм (2020), la estigmatización de los migrantes obedece a la superabundancia de información sobre la cual hay nulo control por parte de los medios de comunicación social; así, algunos interlocutores xonófobos crean cuentas falsas para difundir noticias falsas que afectan a las personas en situación de migrantes. La Unesco (2020) señala que es mayor la estigmatización en aquellas personas que son deportadas de Estados Unidos a sus comunidades de origen.

\section{La comunicación digital para las organizaciones}

Las organizaciones utilizaban internet para su comunicación, en principio, con páginas web que presentaban en su mayoría información estática, es decir, usaban la comunicación unidireccional conforme a los objetivos e intereses de la organización, sin considerar las necesidades del usuario. Posteriormente, con la comunicación de doble vía, se generaron otro tipo de vínculos, a partir de los datos de contacto que el visitante dejaba al mostrarse interesado en el tema, el uso de redes sociodigitales, además del incentivo del diálogo entre la organización y sus seguidores, esto es, la interacción. Así mismo, ha cobrado relevancia el mensaje, la participación y el acceso ilimitado e inmediato a la información (Chávez-Ángeles \& Sánchez-Medina, 2013). Derivado de lo anterior se han ido conformando categorías que se analizaron para comprender la comunicación organizacional, sus alcances y limitaciones. Así, la relación ahora entre las organizaciones y sus seguidores se ha tornado más personal y cercana, tanto para el logro de sus objetivos como para el logro del bien común.

La comunicación digital para las organizaciones es utilizada como un mecanismo que hace posible la interacción y vinculación con los grupos de interés, con el fin último de construir comunidad y obtener beneficios para todos a partir de la colaboración (Sánchez et al., 2018). Es decir, ya no se trata solo de estar en internet, sino de tener presencia en redes sociales para cumplir con una estrategia de comunicación de alto impacto que no solo transmita mensajes, sino que construya vínculos. Al final debe ser posible comunicarse por diversos canales y con distintos lenguajes de manera simultánea (Herrera \& Arévalo-Martínez, 2014). Sin embargo, para construir estos vínculos es muy importante tener un mensaje central que sea de alto impacto, que genere valor para todos los involucrados y que permita crecer en comunidad; de ahí la inclusión de la responsabilidad social organizacional. El mensaje central tiene que estar acorde a la cultura interna, a los valores y a las prácticas de la organización, pues de esta manera puede ser creíble y reproducido (Sánchez-Hervás \& Subiela-Hernández, 2020). La construcción ética de una cultura interna en las organizaciones es la condición de posibilidad para animar la identidad y verdaderos vínculos estables con diferentes grupos sociales (Muñoz et al., 2019).

La evaluación de la comunicación digital de las organizaciones se puede medir con indicadores de presencia, relevancia e interacción (Arévalo-Martínez \& Rebeil, 2017); además, habría que valorar si los contenidos publicados en las redes sociales digitales cumplen con preceptos éticos fundamentales (Del Prado Flores, 2014) y con la conciencia ética de que sus mensajes tienen un impacto ineludible en sus audiencias (Del Prado Flores, 2018), siempre y cuando estén alineados a los capitales que se desea impactar en la organización (Arévalo-Martínez, 2019). Esta consideración forma parte del análisis cualitativo de la comunicación digital para las organizaciones, y marca pautas para su actuación en la relación con sus audiencias, usuarios, colaboradores, etc., no solo atendiendo en 


\section{DISERTACIONES}

AVANCES

el día a día las situaciones que se le presenten, sino para lograr las metas planteadas considerando siempre la proactividad de los usuarios en función del bien común (Calleja-Reina et al., 2018).

La necesidad ética de comunicarse de manera directa y constante, como una forma de enriquecer experiencias compartidas, ha animado a las organizaciones a una interacción inteligente en redes sociales (Capriotti et al., 2019; Monserrat-Gauchi et al., 2017; Rodríguez et al., 2015), de lo cual se desprenden investigaciones que analizan categorías como compartir, conversar, comunicar y cooperar (Del Pino \& Galán, 2010), similares a este estudio. La importancia que tiene generar diálogo en redes sociales, que en esta investigación se mide como conexión, también ha sido estudiada al igual que la evaluación de las condiciones de posibilidad de generar comunidades y medir engagement (Capriotti, et al., 2019), que en este trabajo se mide como colaboración.

Diversas investigaciones sobre comunicación en redes sociales por parte de las organizaciones han ponderado la presencia, la actividad, la frecuencia, la interacción y la relevancia de los mensajes entre otras dimensiones. La variable de presencia en redes sociales se ha utilizado para referirse al número de publicaciones o post que se realizan (Gutiérrez et al., 2018). En otros estudios se ha denominado como actividad, aunque igualmente ha servido para cuantificar el número de publicaciones en redes sociales (Capriotti et al., 2019; Guzmán et al., 2013; González-Bustamante, 2015) o la frecuencia de actualización (Sánchez \& Pinochet, 2017). La variable relevancia surge del hecho de que la organización pueda generar contenido de valor, como ya ha sido investigada, para evidenciar la existencia de influencia en el usuario (Lara-Navarra et al., 2018). La categoría interacción, utilizada en esta investigación, se divide en cuatro indicadores: proximidad, monitoreo, conexión y colaboración, los cuales se desprenden de los niveles de la pirámide de la calidad de comunicación (Arévalo-Martínez \& Rebeil, 2017).

Por otra parte, la medición del valor que tiene el contenido en redes sociales se ha hecho relacionando las métricas de que el usuario comparta el contenido y se pueda evaluar su grado de influencia (Lara-Navarra et al., 2018; Sánchez et al., 2018); por ello, en esta investigación se consideraron las categorías de interacción y reacción vs. contenido.

\section{Metodología}

Esta investigación tuvo como objetivo analizar la comunicación digital de la oım en Facebook y Twitter a partir de la medición de indicadores de presencia, relevancia y reacción en cuanto al análisis del contenido de la interacción en dichas redes sociales digitales respecto a los tres objetivos de la oım: promover la cooperación internacional, encontrar soluciones y ofrecer ayuda humanitaria. Las preguntas de investigación fueron: 1) ¿Cómo es la presencia de los mensajes de la oım en sus redes sociales? 2) ¿Qué relevancia tiene el contenido publicado por la oım en redes sociales para sus usuarios? 3) ¿Cuál es la reacción que generan los contenidos de la oım entre sus usuarios de Facebook y Twitter? 4) ¿En qué medida la interacción de la oı con sus usuarios de redes sociales logra llegar a la colaboración? 5) ¿En qué proporción los comentarios que recibe la oım en sus redes sociales son positivos? 6) ¿Qué contenidos reciben el mayor número de comentarios? 7) ¿Qué contenidos reciben el mayor número de reacciones? 


\section{DISERTACIONES}

\section{AVANCES}

Los enunciados hipotéticos que se plantearon fueron cuatro:

H1: la relevancia del contenido en 2020 en ambas redes sociales estuvo más enfocada en los intereses de los usuarios que en 2019.

H2: la interacción que tiene la oım en 2020 con sus usuarios, particularmente referida a la colaboración, es mayor en Facebook que en Twitter.

H3: los contenidos en 2020 con mayor número de comentarios están relacionados con un mismo objetivo de la oım en ambas redes sociales.

H4: el mayor número de reacciones en 2019 y 2020, en ambas redes sociales, se concentra en un solo objetivo de la oıм.

La primera fase de la investigación cuantitativa consistió en medir las variables de presencia, relevancia y reacciones. La presencia (frecuencia) y relevancia de las publicaciones en redes sociales ya ha sido estudiada (Capriotti et al., 2019; Sánchez \& Pinochet, 2017; Guzmán et al., 2013; González-Bustamante, 2015). La segunda fase de investigación se hizo a través del análisis de contenido para determinar la interacción, la cual ha sido considerada de alto valor en la investigación para establecer categorías (Bardin, 1996; Mayring, 2000; Pérez, 1994; Krippendorff, 1990), que permitan hacer inferencias al relacionarlas con otras. El análisis de contenido en redes sociales ha sido utilizado en investigaciones sobre organizaciones (Capriotti et al., 2019; Monserrat-Gauchi et al., 2017; Sánchez et al., 2018; Almansa-Martínez \& Fernández-Torres, 2011; Fernández et al., 2017); mientras que la interacción en redes sociales también ya ha sido estudiada (Capriotti et al., 2019; Monserrat-Gauchi et al., 2017; Rodríguez et al., 2015; Del Pino \& Galán, 2010). La propuesta en esta investigación está en las categorías que la conforman: proximidad, monitoreo, conexión y colaboración. La tercera fase de la investigación consistió en analizar el cruce de las categorías de comentarios vs. contenido y reacciones vs. contenido. Este tipo de análisis es fundamental para identificar el peso que tiene el contenido como detonador de la interacción (Lara-Navarra et al., 2018; Sánchez et al., 2018). Las categorías utilizadas en esta investigación con su definición operacional hasta el detalle de cómo fueron registradas se muestran en la tabla 1. 


\section{DISERTACIONES}

AVANCES

Comunicación y controversias sociocientíficas en salud y medio ambiente

ISSN: $1856-9536$

Doi: https://doi.org/10.12804/revistas.urosario.edu.co/disertaciones/a.10389

Volumen 14, Número 2 / Julio-diciembre 2021

Versión PDF para imprimir desde

http://revistas.urosario.edu.co/index.php/disertaciones

Tabla 1. Categorías de análisis

\section{Categoria/ variable}

Presencia

redes sociales

Análisis del

Relevancia contenido publicado para identificar qué objetivo cumple

Reacciones de los

Reacción usuarios en las redes sociales

\section{Definición operacional}

Es la periodicidad, entendida como el número de actualizaciones de información por día, ya sea publicaciones de imágenes, videos o texto. Se registra numéricamente como el promedio de publicaciones cada 7 días.

Es el objetivo que tiene el contenido publicado. Del $100 \%$ de contenido publicado en el periodo analizado, se registró numéricamente el porcentaje que estuvo relacionado con el cumplimiento de los objetivos o intereses propios de la organización y el porcentaje que estuvo dirigido a la atención de las necesidades del usuario.

Es la medición del número de reacciones recibidas a cada publicación en cada una de las semanas analizadas. En el caso de Facebook, se cuantificó la cantidad de me gusta, me encanta, me divierte, me asombra y me enoja. En el caso de Twitter, se cuantificó la cantidad de me gusta, retuits y comentarios. Se registró numéricamente como el promedio de reacciones recibidas cada semana analizada en cada red social.

1. Proximidad es la cercanía y personalización de la información publicada, es decir, el trato directo que tiene la organización hacia sus usuarios, brindándoles respuesta inmediata a comentarios, inquietudes y cuestionamientos. Se registró como alta, media o baja, conforme a parámetros de tiempo. ${ }^{\mathrm{a}}$

Calidad de los vínculos establecidos

Interacción por la organización con los usuarios en redes sociales
2. Monitoreo. Identificación de interlocutores o líderes de opinión relevantes para la organización. Se registró como alto, medio o bajo, conforme a parámetros de efectividad. ${ }^{b}$

3. Conexión. Tener conversaciones con distintos usuarios, promover el diálogo. Se registró como alta, media o baja, conforme a parámetros de participación. ${ }^{c}$

4. Colaboración. Capacidad de escucha de la organización y de aporte orientado a la realización de un fin común. Se registró como alta, media o baja, conforme a parámetros de vinculación. ${ }^{d}$
Es el análisis de contenido realizado a los comentarios recibidos en las publicaciones de la ом con el fin de clasificarlos como positivos o negativos. Se realizó al identificar la presencia de ideas a favor $(+)$ o en contra $(-)$, aprobación (+) o desaprobación (-) de sus acciones, y quejas (-) o agradecimiento/reconocimiento $(+)$ a su labor. Se registró numéricamente como el promedio por semana de comentarios positivos vs. negativos recibidos en cada red social.

Es el análisis de las publicaciones con mayor cantidad de comentarios recibidos cada semana del periodo de análisis, considerando el impacto del contenido respecto a qué objetivo de la oım se trata. Se registró numéricamente como el porcentaje de contenidos de cada uno de los tres objetivos de la oım con mayor interacción (comentarios) en el periodo analizado en cada red social. 


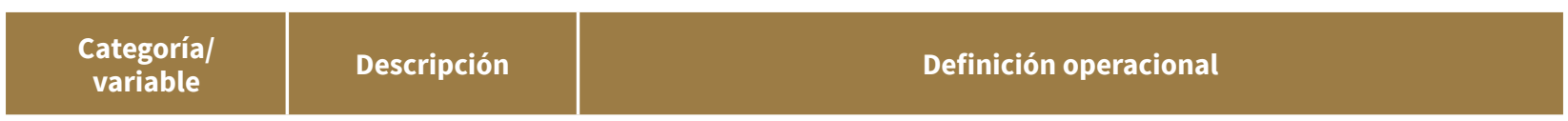

Es el análisis de las publicaciones con mayor cantidad de reacciones positivas

Reacción vs. contenido
Impacto del contenido en la reacción (me gusta) recibidas cada semana del periodo de análisis, considerando el impacto del contenido respecto a qué objetivo de la oım se trata. Se registró numéricamente como el porcentaje de las reacciones recibidas en Facebook (me gusta, me encanta, me divierte, me asombra y me enoja) y en Twitter (me gusta) vs. los contenidos de cada uno de los tres objetivos de la oıм por año.

\begin{abstract}
a Parámetros de tiempo. Alta: la organización responde habitualmente o casi siempre las preguntas y los comentarios formulados por sus audiencias clave, en un lapso entre 3 y 24 horas, recurriendo a señas de reconocimiento y trato personal (por ejemplo, se tutea a la audiencia, se emplea el saludo). Media: la organización responde solo algunas veces las preguntas y los comentarios formulados por sus audiencias clave, en un lapso entre 24 y 72 horas, recurriendo o no a señas de reconocimiento y trato personal. Baja: la organización casi nunca responde las preguntas y los comentarios formulados por sus audiencias clave, pudiendo superar las 72 horas en caso de retroalimentación, recurriendo o no a señas de reconocimiento y trato personal.

${ }^{\mathrm{b}}$ Parámetros de efectividad. Alto: la organización identifica líderes de opinión manifestando interés hacia ellos y tomándolos en cuenta (acercamiento, preguntas) de cara al cultivo de una relación sostenida en el tiempo conforme temáticas específicas. Medio: la organización identifica líderes de opinión solo de cara al tratamiento de temas o el apalancamiento de mensajes y acciones concretas, en un momento determinado y sin continuidad en el tiempo. Bajo: la organización rara vez o nunca se distingue por identificar y menos aún establecer vínculos con líderes de opinión.

c Parámetros de participación. Alta: la organización habitualmente o casi siempre acude a un estilo apelativo en el momento de presentar el contenido a sus audiencias, ya sea en forma de historias o preguntas de partida, con el ánimo de compartir ideas y sobre todo generar comentarios. Media: la organización utiliza en algunas ocasiones el estilo apelativo al momento de presentar el contenido a sus audiencias, mientras que en otras oportunidades decanta por un tono más bien impersonal, limitándose a la notificación sobre hechos o hallazgos. Baja: la organización rara vez o nunca recurre a un estilo apelativo frente a sus audiencias, mostrando un tono distante en la presentación de los contenidos, sin propiciar la generación de comentarios o la expresión de opiniones.

d Parámetros de vinculación. Alta: la organización apela abiertamente al conocimiento de sus audiencias mediante la creación y el desarrollo frecuente de eventos virtuales que promueven la participación (foros, encuestas, concursos), emitiendo comentarios positivos hacia sus seguidores durante y después de la realización de estas actividades. Media: la organización solo algunas veces apela directamente a sus audiencias, pudiendo involucrarlas a través de actividades de colaboración y participación (foros, concursos, encuestas), aunque sin emitir mayor retroalimentación durante o después de la actividad. Baja: la organización rara vez o nunca estimula la participación de sus audiencias, mostrando barreras de acceso o escasa apertura a las ideas que provienen del medio externo.
\end{abstract}

Fuente: adaptado de Arévalo-Martínez y Rebeil (2017).

Los datos se recopilaron del contenido de la cuenta de la oım en Facebook y Twitter durante los meses de julio, agosto y septiembre de 2019, comparados con los meses de octubre, noviembre y diciembre de 2020. Los meses analizados en 2020 no pudieron ser los mismos de 2019 por condiciones ajenas a los investigadores derivadas de la pandemia de covid-19. Sin embargo, los periodos de los años analizados comprenden 13 semanas, por lo que se procedió a realizar el comparativo. La recogida de datos para el análisis cuantitativo y el análisis de contenido se hizo de manera directa por parte de los investigadores, registrándolos en una base de datos. Se analizaron un total de 377 publicaciones con 446 comentarios en Facebook y 122 publicaciones con 262 comentarios en Twitter.

\title{
Resultados
}

En primer lugar, se revisó la presencia en ambas redes sociales, comparando 2019 y 2020, como puede verse en la figura 1 para Facebook y en la figura 2 para Twitter. En ambas redes sociales el incremento de publicaciones por día fue de más del $100 \%$ en 2020 respecto a 2019. En Facebook se registró un incremento promedio del $113 \%$ en 2020 respecto a 2019. En el caso de Twitter, el incremento promedio fue del $131 \%$ en 2020 respecto a 2019. 


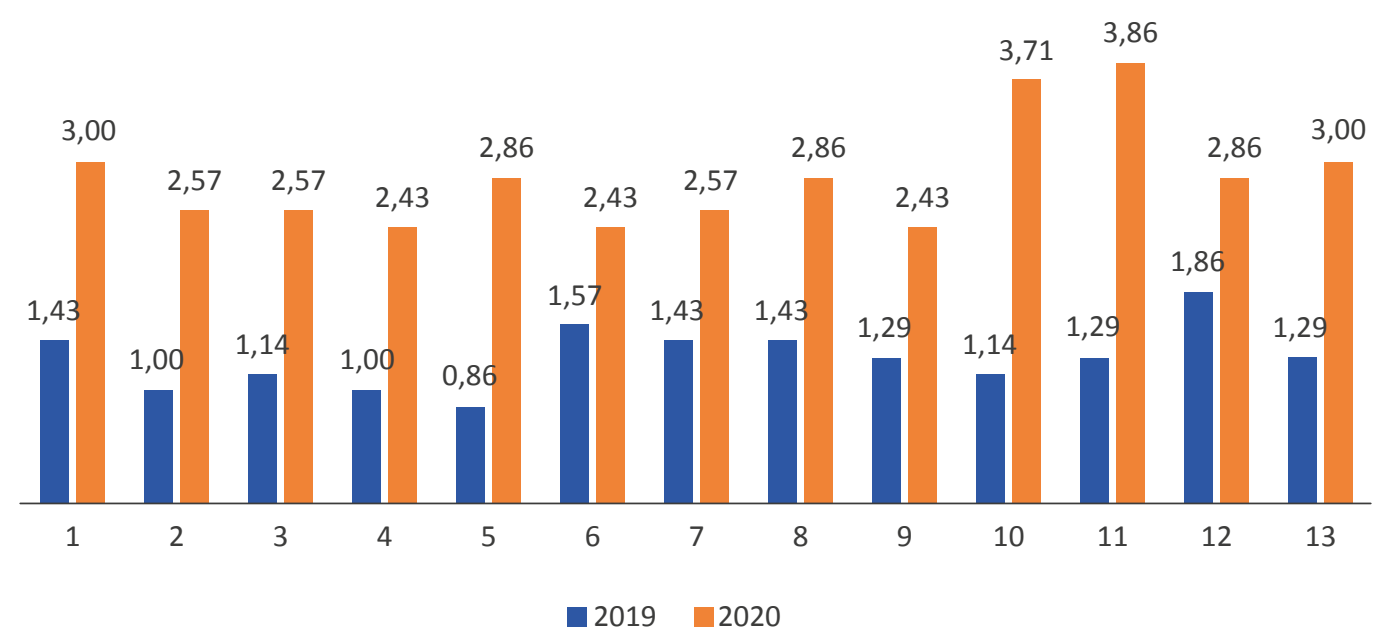

Figura 1. Promedio de publicaciones al día en Facebook

Fuente: elaboración propia.

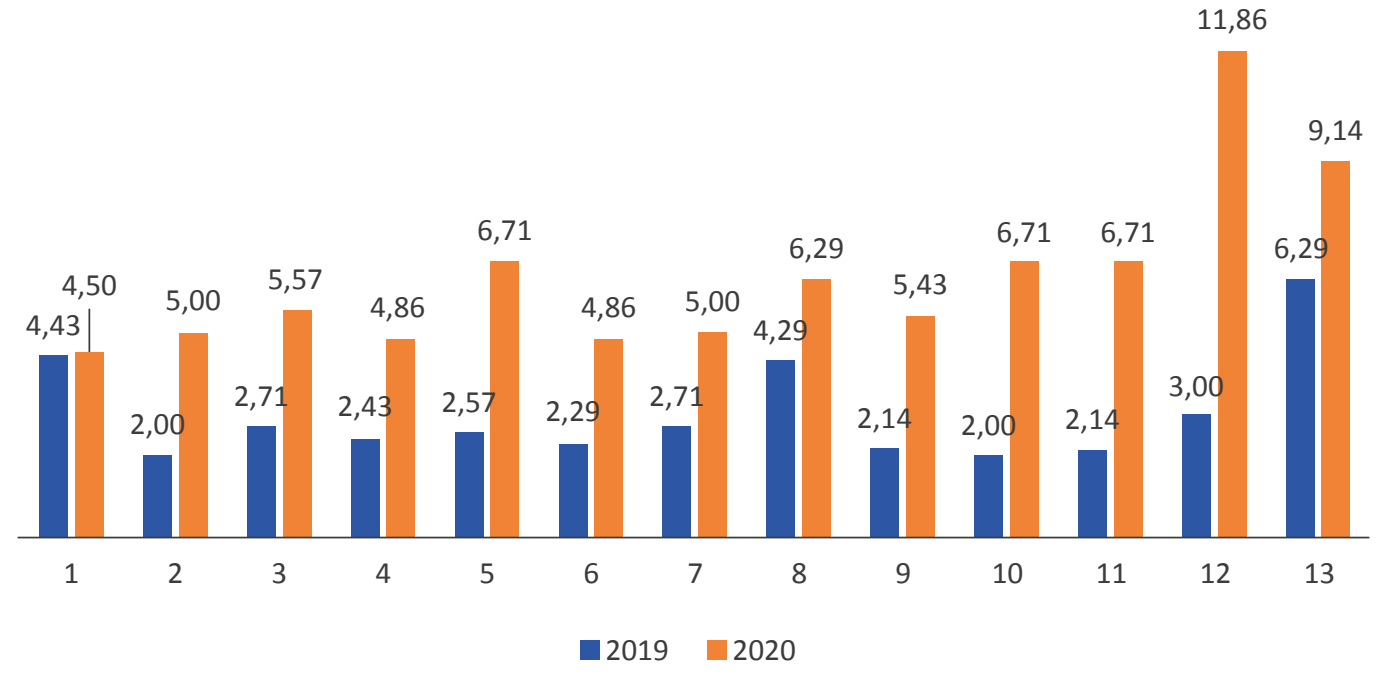

Figura 2. Promedio de publicaciones al día en Twitter

Fuente: elaboración propia.

En cuanto a la relevancia de la información, se analizó si el contenido tiene un mayor valor para la organización, en este caso la oım o para el público (figuras 3 y 4). Como puede observarse, también hubo cambios en ambas redes sociales con mayor enfoque de contenido de valor para el público en 2020, siendo en Twitter más evidente, 


\section{AVANCES}

con el $100 \%$ de las semanas con mayor contenido de relevancia para el público. Con base en lo anterior, la H1 sí se comprueba, dado que la relevancia del contenido en 2020 en ambas redes sociales estuvo más enfocada que en 2019 en los intereses de los usuarios, con 69,2\% en Facebook y con un $100 \%$ en Twitter.

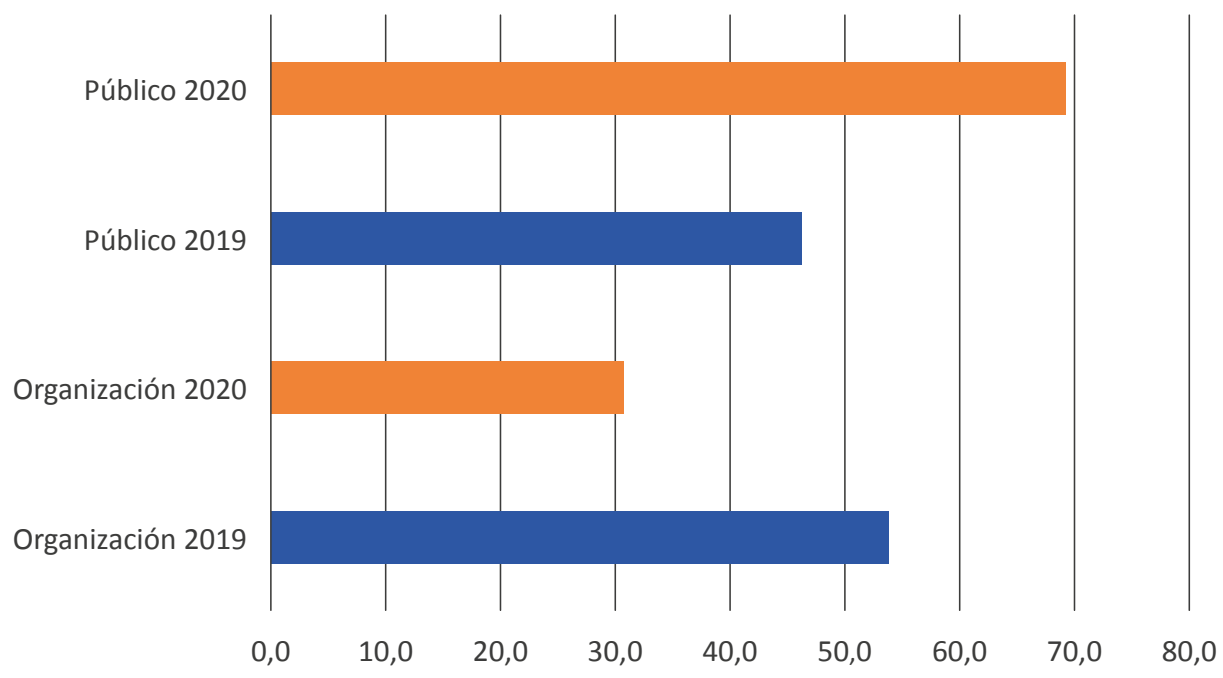

Figura 3. Relevancia del contenido en Facebook

Fuente: elaboración propia.

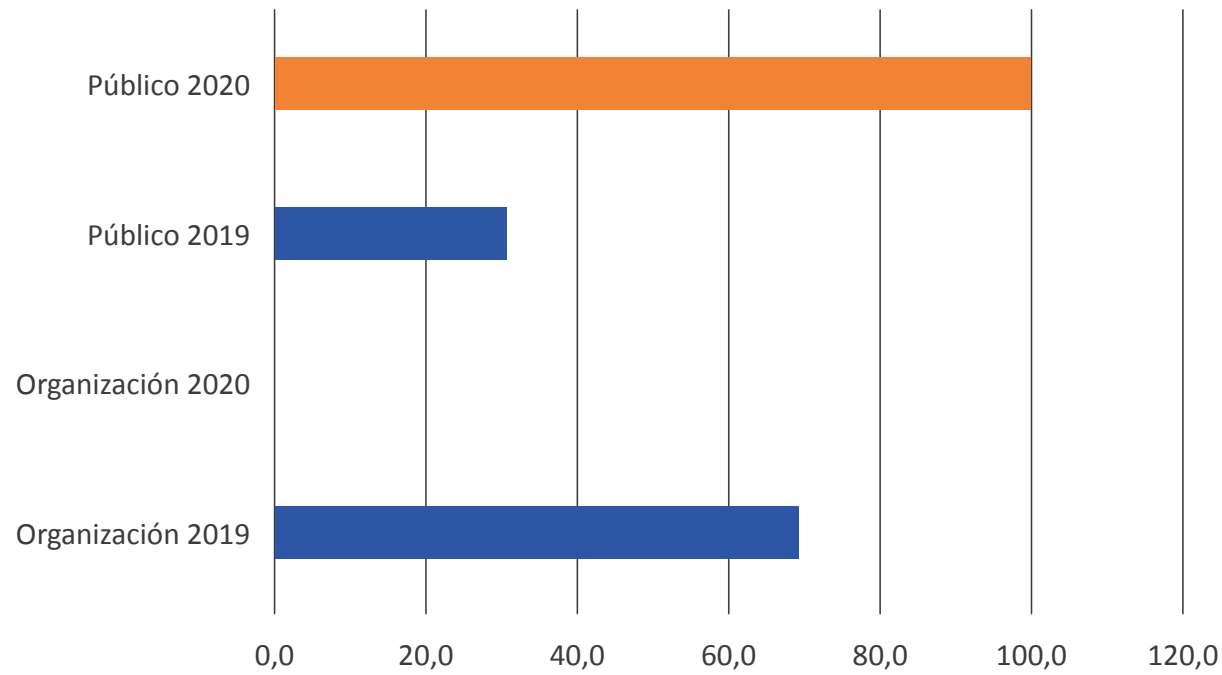

Figura 4. Relevancia del contenido en Twitter

Fuente: elaboración propia. 
En cuanto a las reacciones que tienen los usuarios frente a las publicaciones en Facebook (figura 5), se observó que se centran en aprobar el contenido con un me gusta o me encanta, sin dar mayor peso a otro tipo de emociones. Este resultado comparativo de 2020 vs. 2019 muestra en Facebook un incremento del 1,7\% en me gusta; un incremento del 14,9\% en me encanta; una reducción del 99,8\% en me divierte; una reducción del $61,5 \%$ en me asombra; un reducción del 2,4\% en me entristece, y una reducción del 64,7\% en me enoja.

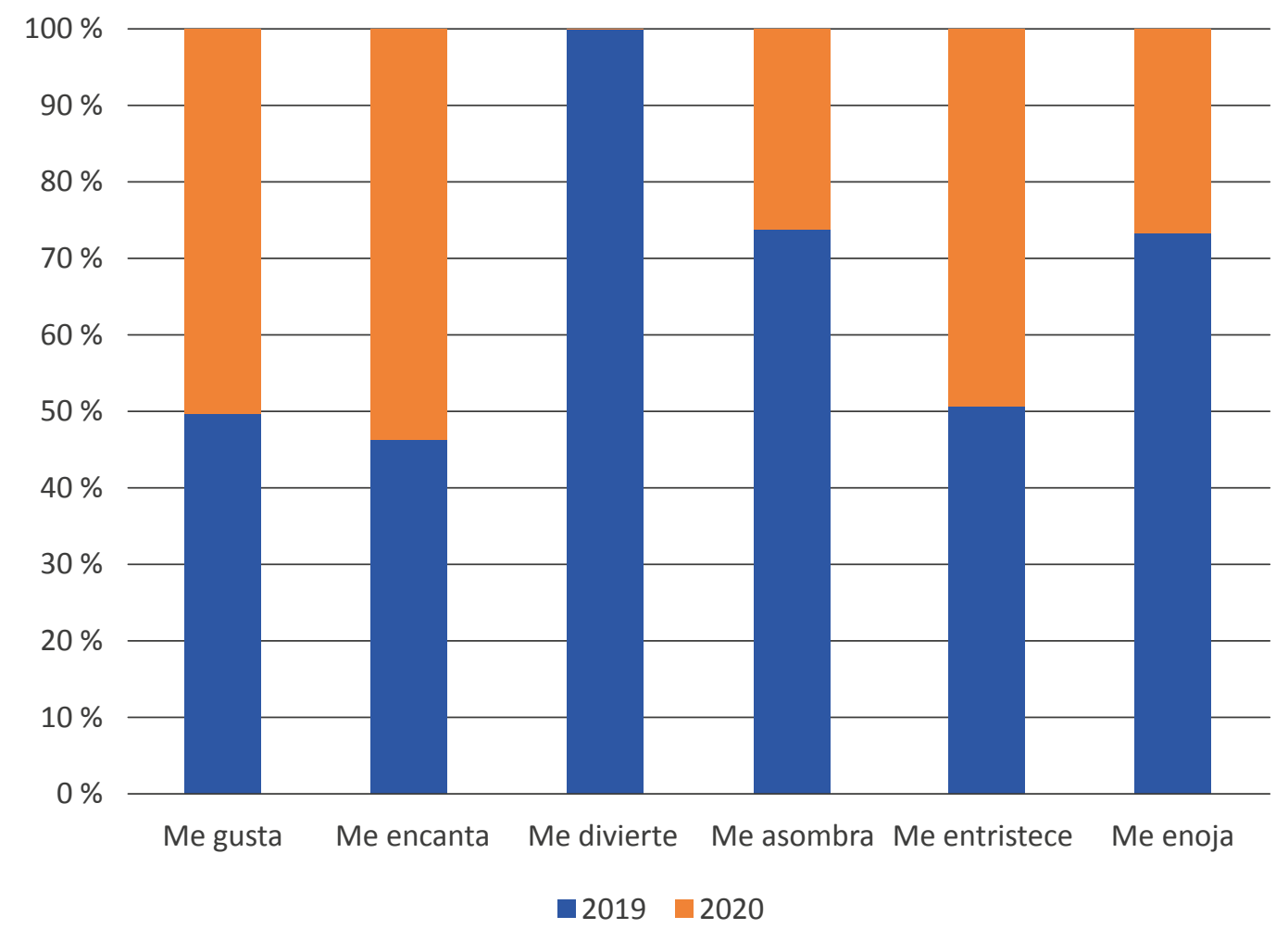

Figura 5. Reacciones a la publicación con mayor interacción por semana en Facebook

Fuente: elaboración propia.

En el caso de Twitter, sobre el mayor número de reacciones se encontró que las emociones que causaron sus publicaciones en cada semana analizada (figura 6) en todos los casos tuvieron un incremento en 2020 respecto a 2019: incremento del $4,5 \%$ en me gusta, incremento del $48,8 \%$ en retuits e incremento del $4,7 \%$ en comentarios. 


\section{DISERTACIONES}

AVANCES

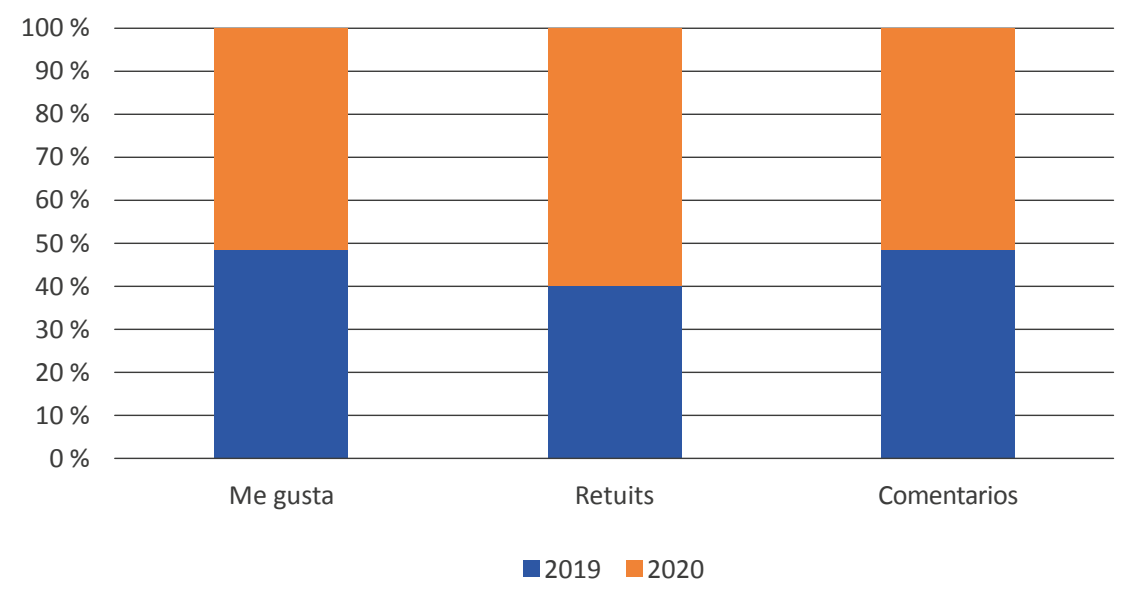

Figura 6. Reacciones a la publicación con mayor interacción por semana en Twitter

Fuente: elaboración propia.

Con respecto a la interacción, como se puede ver en las figuras 7 y 8, en el caso de cercanía y personalización en ambas redes sociales tanto en 2019 como en 2020 es baja, no hay respuestas en las redes sociales a los comentarios de los usuarios por parte de la oıм. Sobre escucha y monitoreo, empeoró en 2020 en ambas redes sociales, al quedar en cero en ambas redes sociales. Sobre conexión, permaneció baja y con un incremento del $800 \%$ en publicaciones con nivel medio en Facebook en 2020; mientras que en Twitter siguió baja. Finalmente, sobre colaboración, en ambas redes sociales aún no se llega a un nivel alto de colaboración y el nivel medio de 2020 se incrementó un $200 \%$ en Twitter, preponderando el nivel bajo en 2019 y 2020 en ambas redes sociales. Con base en lo anterior, la H2 sí se comprueba, ya que la interacción que tiene la oı con sus usuarios en 2020, particularmente referida a la colaboración, fue mayor en Facebook que en Twitter.

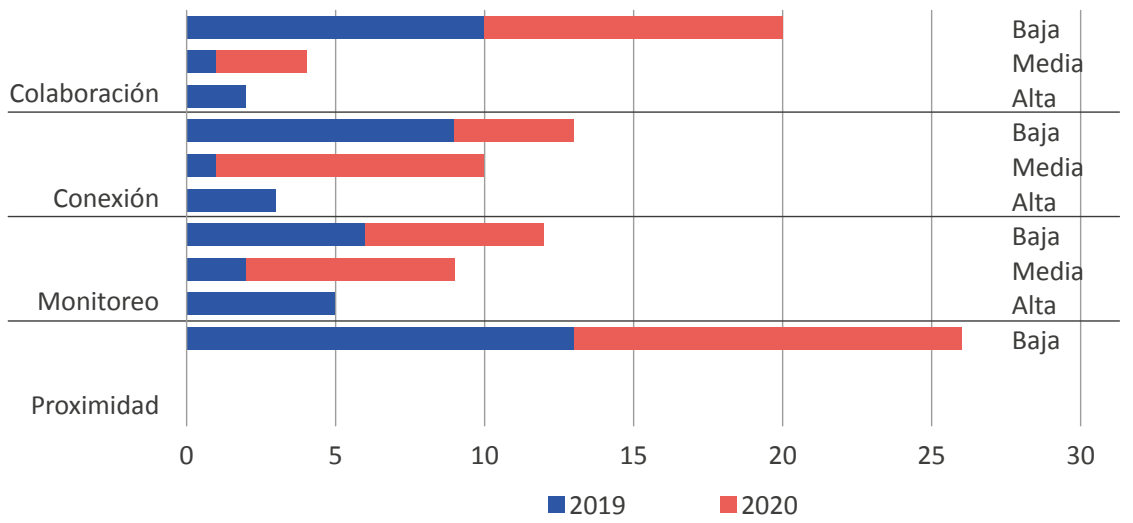

Figura 7. Interacción en Facebook

Fuente: elaboración propia. 


\section{DISERTACIONES}

AVANCES

Comunicación y controversias sociocientíficas en salud y medio ambiente

ISSN: $1856-9536$

Doi: https://doi.org/10.12804/revistas.urosario.edu.co/disertaciones/a.10389

Volumen 14, Número 2 / Julio-diciembre 2021

Versión PDF para imprimir desde

http://revistas.urosario.edu.co/index.php/disertaciones

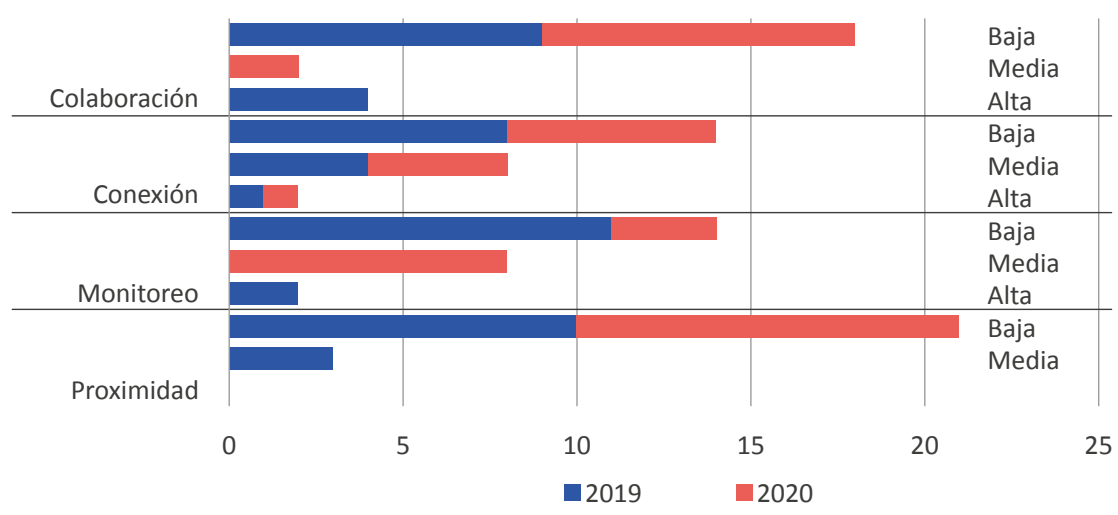

Figura 8. Interacción en Twitter

Fuente: elaboración propia.

Al cruzar la cantidad de comentarios con respecto a los contenidos de las publicaciones en Facebook (figura 9) se observa que incrementó en un 100 \% la atención en 2020 hacia la promoción de la cooperación internacional, en mucho debido a la pandemia, aunque se redujeron en un $75 \%$ los contenidos referentes a la aportación de soluciones y se redujo en un $50 \%$ la oferta de ayuda humanitaria, que son los otros dos objetivos de la oim. En el caso de Twitter (figura 10), el aumento en la atención en 2020 se presentó en un $373 \%$ en los contenidos sobre la oferta de ayuda humanitaria, pero se redujeron en un $29 \%$ la promoción de la cooperación internacional y en un $41 \%$ la aportación de soluciones, los otros dos objetivos de la oım. Con base en lo anterior, la H3 no se comprobó, porque los contenidos con mayor número de comentarios de 2020 no estuvieron dirigidos a un solo objetivo de la oІm; en el caso de Twitter, estuvieron relacionados con el objetivo de ofrecer ayuda humanitaria, pero en Facebook estuvieron relacionados con la promoción de la cooperación internacional.

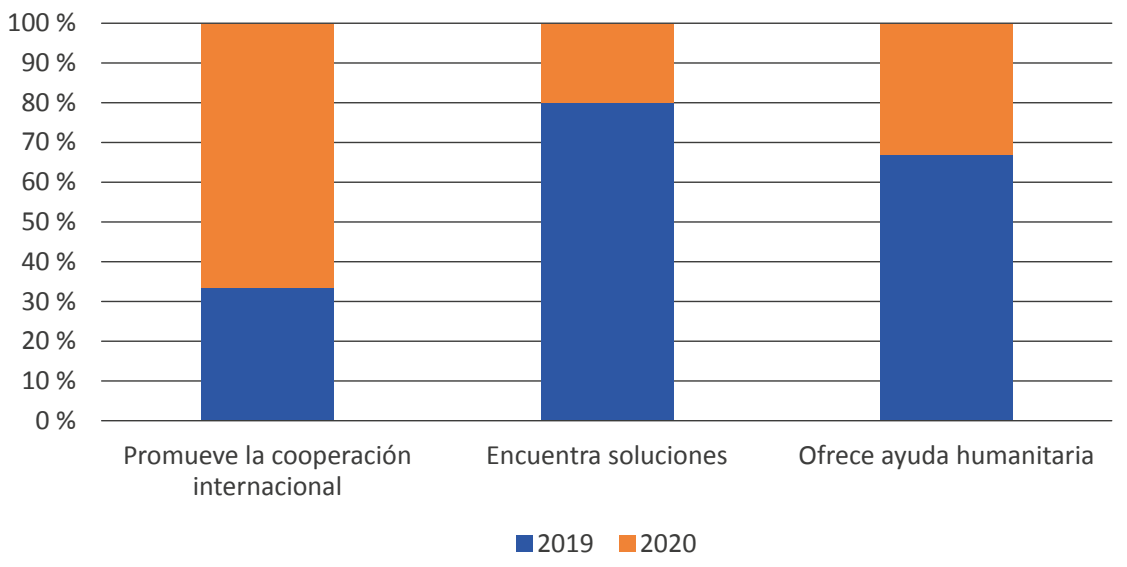

Figura 9. Contenido de la publicación con mayor número de comentarios en Facebook

Fuente: elaboración propia. 


\section{DISERTACIONES}

AVANCES

Comunicación y controversias sociocientíficas en salud y medio ambiente

ISSN: $1856-9536$

Doi: https://doi.org/10.12804/revistas.urosario.edu.co/disertaciones/a.10389

Volumen 14, Número 2 / Julio-diciembre 2021

Versión PDF para imprimir desde

http://revistas.urosario.edu.co/index.php/disertaciones

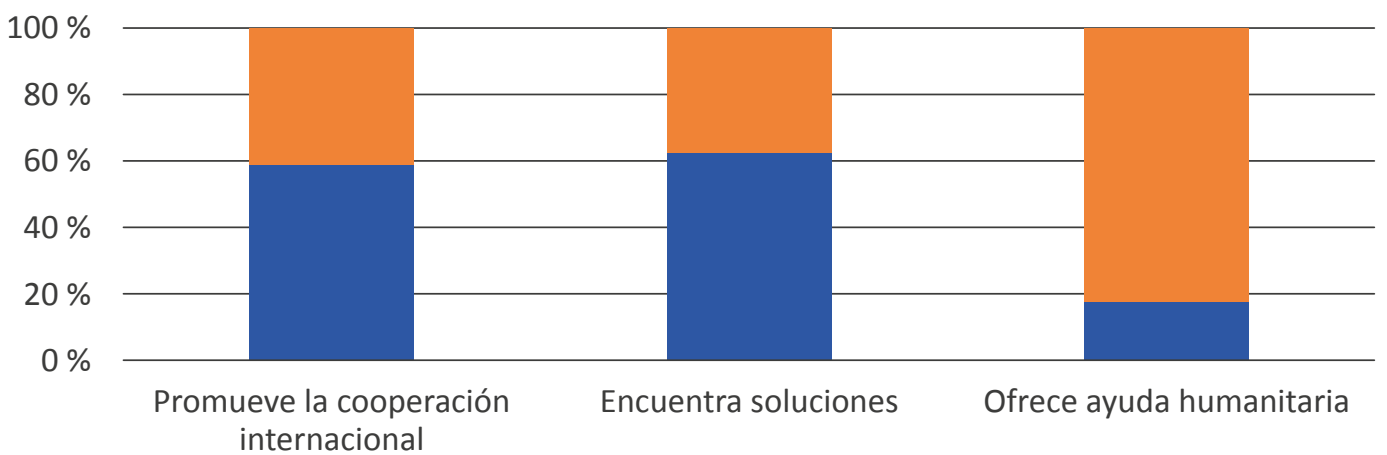

- $2019 \square 2020$

Figura 10. Contenido de la publicación con mayor número de comentarios en Twitter

Fuente: elaboración propia.

Con respecto a la reacción vs. el contenido de las publicaciones de la oıм, como se observa en la figura 11 en Facebook durante 2019 para el $90 \%$ de las publicaciones sobre la promoción de la cooperación internacional, el $88 \%$ de contenidos sobre encontrar soluciones y el $94 \%$ de la oferta de ayuda humanitaria recibieron como reacción me gusta; seguido de me encanta para el $5 \%$ para los contenidos de promoción de ayuda humanitaria, el $6 \%$ en contenidos de encontrar soluciones y el $6 \%$ en contenidos de ayuda humanitaria.

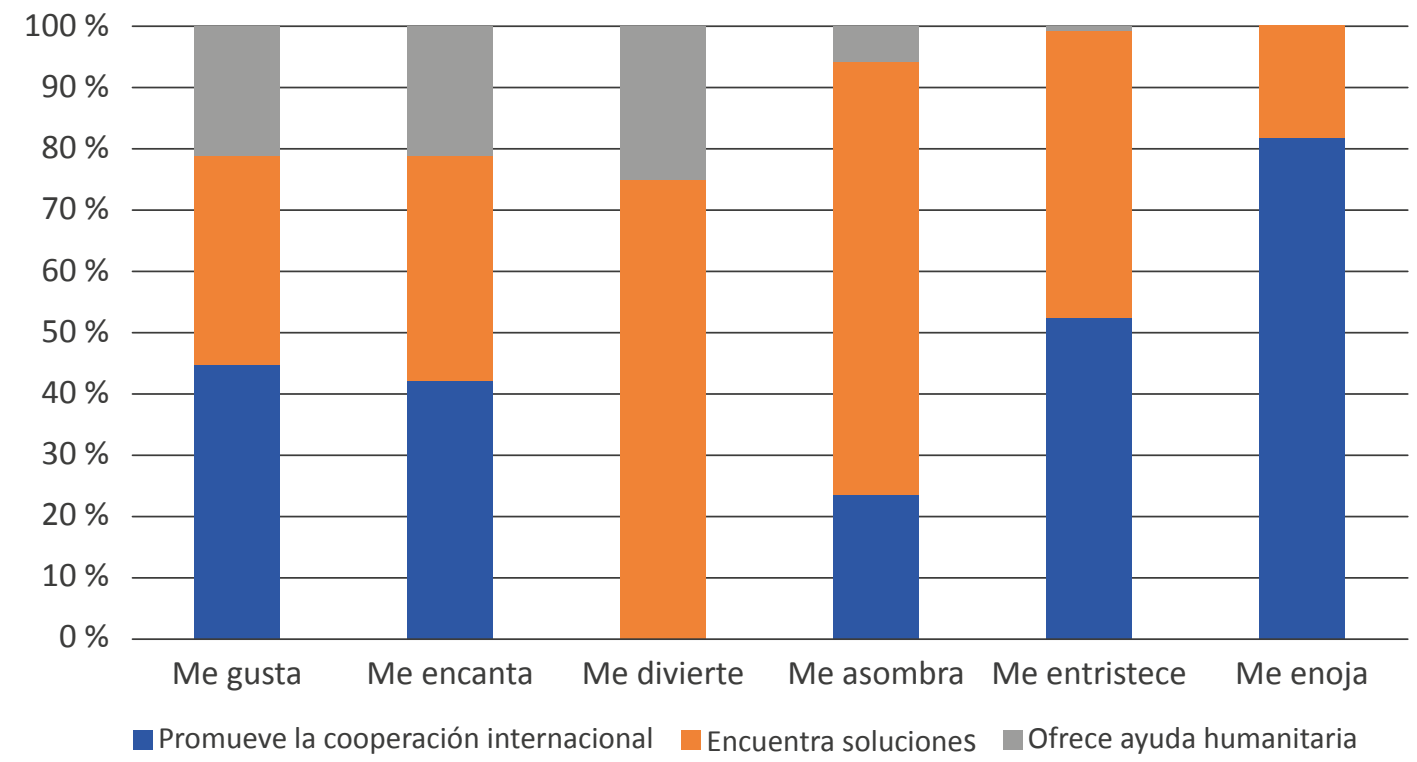

Figura 11. Contenido de la publicación vs. reacción en Facebook, 2019

Fuente: elaboración propia. 
En la figura 12 con respecto a las reacciones en Facebook, en 2020 se observó que recibieron como reacción me gusta el $93 \%$ de las publicaciones sobre la promoción de la cooperación internacional, el $89 \%$ de contenidos sobre encontrar soluciones y el $78 \%$ de la oferta de ayuda humanitaria; mientras que recibieron como reacción me encanta el $6 \%$ para los contenidos de promoción de ayuda humanitaria, el $11 \%$ en contenidos de encontrar soluciones y el $1 \%$ en contenidos de ayuda humanitaria. Es decir, en 2019 las reacciones con otro tipo de emociones, más allá de me gusta y me encanta, fueron utilizadas por un $6 \%$ o menos de los usuarios en cada tipo de contenido. En 2020 no hubo ningún otro tipo de reacción para la promoción de la cooperación internacional y la oferta de soluciones, aunque en el caso de los contenidos de oferta de ayuda humanitaria sí hubo un $20 \%$ de reacciones de tristeza, un $1 \%$ de enojo y un $1 \%$ de asombro.

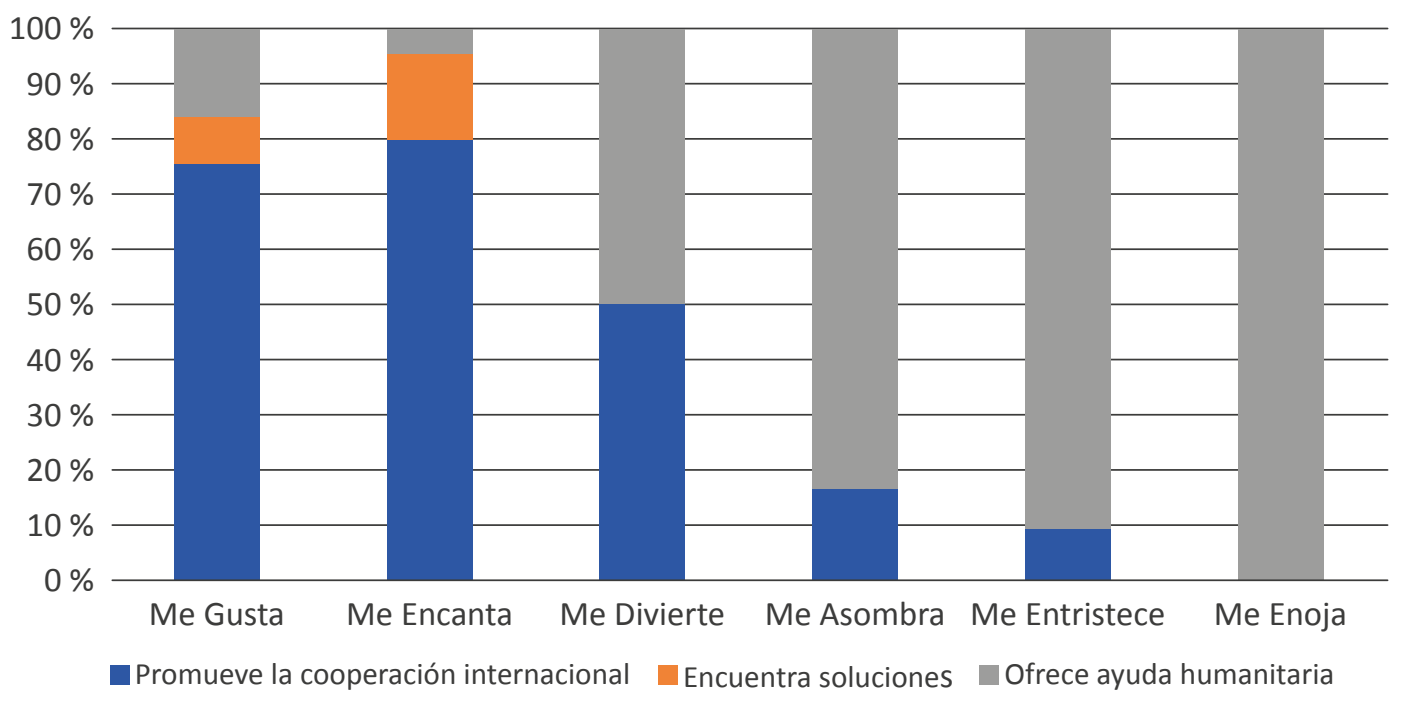

Figura 12. Contenido de la publicación vs. reacción en Facebook, 2020

Fuente: elaboración propia.

En la figura 13, con respecto a Twitter, en 2019 se observó que el contenido que obtuvo la mayor cantidad de me gusta fue el referente a la promoción de la cooperación internacional, con un 83\%; seguido de encuentra soluciones, con un $14 \%$, y ofrece ayuda humanitaria, con un $3 \%$. Para 2020, en Twitter el contenido con mayor cantidad de me gusta fue el de oferta de ayuda humanitaria, con un $53 \%$; seguido de promoción de la cooperación internacional, con un $44 \%$, y el contenido de soluciones, con un $3 \%$. 


\section{DISERTACIONES}

AVANCES

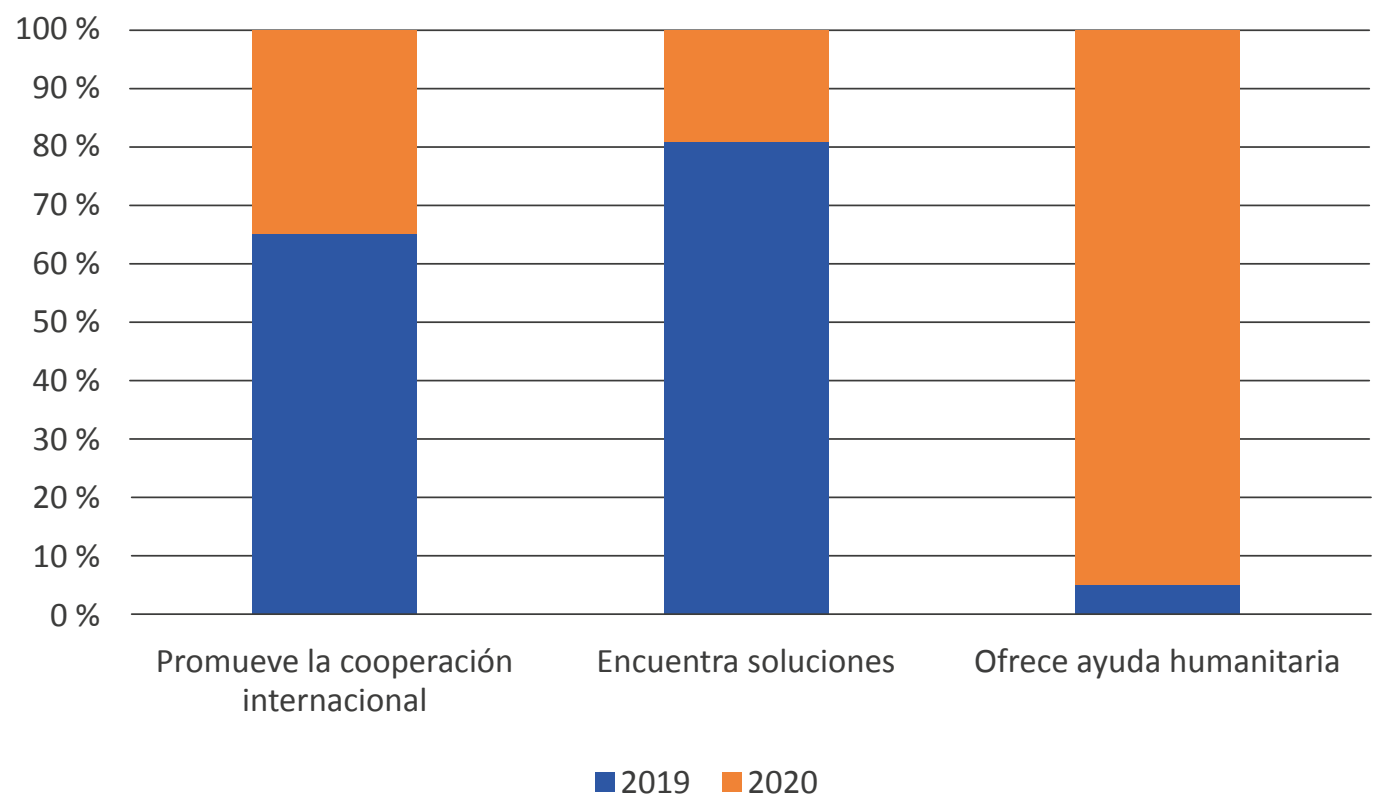

Figura 13. Contenido de la publicación vs. reacción en Twitter, 2019 y 2020

Fuente: elaboración propia.

Con base en lo anterior, la $\mathrm{H} 4$ no se comprueba, porque los contenidos en ambas redes sociales no concentran el mayor número de reacciones en uno solo de los temas, objetivos de la oım. Existe una reacción diferenciada por tipo de contenido en Facebook en 2020, en el caso de la oferta de ayuda humanitaria, que no solo tuvo reacciones positivas de me gusta y me encanta, sino que el $22 \%$ de las reacciones fueron de otro tipo; mientras que en Twitter las reacciones cambiaron de 2019 a 2020, dejando en primer lugar a la promoción de la cooperación internacional en 2019 y a la oferta de ayuda humanitaria en 2020.

Sobre los comentarios recibidos, se analizó el número de comentarios positivos y negativos en cada red social. En la figura 14 se presentan los resultados de Facebook con un mayor número de comentarios positivos (60\% en 2019 y $88 \%$ en 2020) de los usuarios. Entre tanto, en la figura 15 se presentan los resultados de Twitter con solo un $27 \%$ de comentarios positivos en 2019 y un $88 \%$ en 2020. De estos datos se interpreta que la revisión que hacen los usuarios de los contenidos no siempre es exhaustiva y sus comentarios, por ello, a veces, no concuerdan con la realidad, pues el contenido no se explica la diferencia en el tipo de comentarios en las dos redes sociales. Se puede tratar o bien del hecho de que el perfil del usuario de Twitter es más crítico, o bien que el impacto de la pandemia y la información presentada por la oı fue relevante para ellos pero de manera diferenciada en cuanto a su percepción positiva o negativa. 


\section{AVANCES}

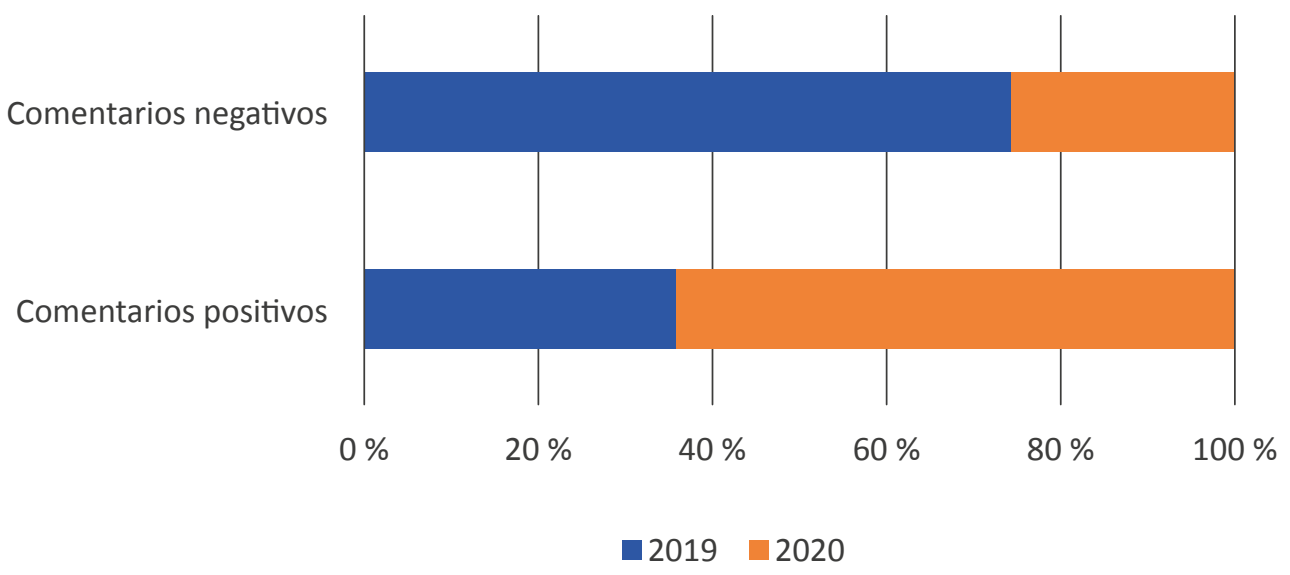

Figura 14. Tipo de comentarios en Facebook promedio por semana

Fuente: elaboración propia.

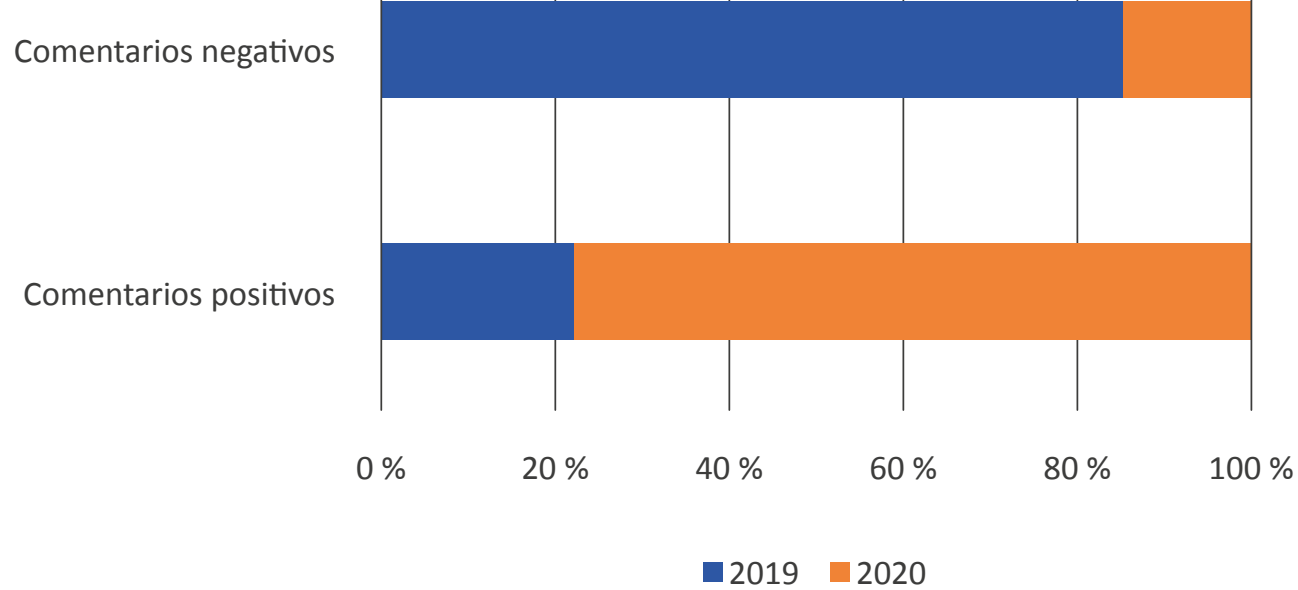

Figura 15. Tipo de comentarios en Twitter promedio por semana

Fuente: elaboración propia.

Como puede verse en los resultados, los objetivos de la oım están presentes en los contenidos de Facebook y Twitter, pero está muy diferenciado la interacción, la reacción y el diálogo que se genera entre los usuarios. Podría decirse que aún está lejos la interacción que lleve a la colaboración en las redes sociales de la oım, particularmente en Twitter, donde los usuarios tienen alguna reacción de aprobación con me gusta, pero no comparten los contenidos o no inician un diálogo para tener una conversación más amplia con otras personas, limitándose a emitir comentarios, en su mayoría negativos. 


\section{DISERTACIONES}

AVANCES

\section{Discusión}

En principio, si la solidaridad implica una fuerte noción de sociabilidad y un sentimiento natural de simpatía, definitivamente, no lo logra la comunicación oım en las redes sociales, menos en Twitter, donde los comentarios son más negativos. Las redes sociodigitales, por la estructura misma, suponen la existencia de comunicación en libertad; ahora bien, por el tipo de contenidos y la problemática humanitaria que implica el fenómeno migratorio, cabría esperar una mayor capacidad de empatía, de colaboración y conciencia social. Por tanto, sería deseable que en ellas surgiera un espacio para brindar apoyo sin pedir nada a cambio, sin tener un beneficio propio, compartir información que pudiera ser de interés para el otro. Sin embargo, como demuestran los datos, particularmente en Twitter, esto no sucede así.

Por el tipo de interacciones que acontecen en las redes sociodigitales, es verificable que se han empeñado en ser espacios para lograr visibilidad, para posicionar puntos de vista, para tener seguidores a partir de generar debate; sin embargo, es cierto que en casos de eventos o circunstancias que afectan a la mayor parte de la población (por ejemplo, los sismos) se genera una interacción muy útil y provechosa para solucionar problemas, pero no se comportan así en la generalidad, no son un espacio de solidaridad en todos los problemas humanitarios, ni con impacto en todos los usuarios. En un tema tan sensible como es la migración, con las implicaciones que tiene en la vida de las personas, las redes sociales digitales no alcanzan a tener como objetivo la incidencia en la formación de criterios para incrementar la socialización, promover la integración, ni siquiera simplemente para la creación de espacios para el diálogo que permitan poner en común los puntos de vista de migrantes y no migrantes, entre ciudadanos de un mundo cada vez más integrado por las redes de información y por la globalización mercantil.

Por otra parte, la búsqueda de una responsabilidad moral individual y colectiva para alcanzar y satisfacer metas comunes no se genera en la oım a través de su comunicación digital, quizá por falta de una poderosa estrategia de comunicación y diálogo. Lo evidenciado en la presente investigación demuestra que solo se trata de comunicación unidireccional en un medio de doble vía; de esta forma, resulta extraño observar que no se crea comunidad ni se promueve el bien común. En este sentido, la comunicación digital que genera la oı no está enfocada en lograr un conciencia cívica, social, ciudadana o de participación, pues no se observó una estrategia de mensajes clave que apuntara hacia una transformación de acciones que ayudara a solucionar problemas. Si bien es cierto que los contenidos de la oı atienden directamente a sus tres objetivos, principalmente en Twitter hacia la cooperación internacional, no se vislumbra cómo se puede convertir en colaboración real por parte de sus seguidores, al mantenerse solo como un medio informativo y no abierto al diálogo plural.

Es decir, hasta ahora la oım ha utilizado esta red sociodigital para la publicación de información que no tiene ningún tratamiento particular y, por lo mismo, no tiene como objetivo ser un medio que promueva la colaboración o el diálogo. Se ha generado una agenda temática que atiende a intereses particulares de la organización y que responde a su propia cultura, pero no se pretende con ello un impacto en las acciones o decisiones de mayor envergadura de los seguidores. 


\section{DISERTACIONES}

AVANCES

Comunicación y controversias sociocientificas en salud y medio ambiente

ISSN: 1856-9536

Doi: https://doi.org/10.12804/revistas.urosario.edu.co/disertaciones/a.10389

Volumen 14, Número 2 / Julio-diciembre 2021

Versión PDF para imprimir desde

http://revistas.urosario.edu.co/index.php/disertaciones

En el caso de Facebook, los contenidos responden de manera más equilibrada a los tres objetivos de la oım; sin embargo, tampoco se logra la colaboración (de hecho, es menor que en Twitter) y se queda solo en cierto nivel de referencia o diálogo en relación con los líderes de opinión.

Es decir, aunque la oım ha demostrado que en su comunicación en Facebook se hace una mayor referencia a los tres objetivos que persigue, aún falta un largo camino por recorrer para diseñar una serie de estrategias de comunicación y mensajes clave que sean aspiracionales para los seguidores y que los haga tener una mayor conciencia de su papel en el desarrollo de diálogos que hagan crecer a la comunidad alrededor de los temas de migración y de la comunidad de migrantes en el mundo. La responsabilidad que cada ciudadano del mundo tiene en este tema no queda de manifiesto en las redes sociodigitales de la oı y tampoco se potencian los esfuerzos que ya se están dando en los planos individual y regional. Tener una alta presencia en redes sociales digitales y preservar la comunicación unidireccional sobre su esencia como organización, sin duda, demuestra una alta congruencia con su propio destino, con su razón de ser y su esencia; pero de ahí a que se logre una verdadera posibilidad de potenciar el impacto en la construcción de una sociedad más incluyente, participativa, de colaboración y de enfoque para el desarrollo de todos, eso es aún una tarea pendiente.

Se comprueba que los contenidos sí hacen referencia a la vulnerabilidad de los migrantes, pero no logran crear un puente entre dicha circunstancia y la realidad de quienes siguen la cuenta de la oı, de tal forma que pudiera llevar a acciones para apoyar directamente a la integración de los migrantes en los países destino. Es decir, aunque los contenidos aporten a la comprensión del problema migratorio y a la búsqueda del respeto a la dignidad de la persona humana, todo ello no se logra traducir en contenidos, imágenes, narrativas o procesos de comunicación en las redes sociales digitales que construyan diálogos donde todos puedan sentirse llamados a la acción y a la promoción del tema entre sus círculos de influencia. No hay evidencia de que exista un verdadero impacto en este tipo de comunicación que ayude a disminuir los problemas de la interacción coétnica y la adaptación de los migrantes, por mencionar un ejemplo. Por ello, se piensa que la disminución en la discriminación y los problemas inherentes a la migración deben formar parte de las estrategias de comunicación digital en este tipo de redes y con estrategias de alto impacto que emprenda la омм para aprovechar su visibilidad e incrementar su influencia global.

En ese sentido, el bajo impacto en los seguidores que tiene la oıм, también se debe a que no promueve la participación activa y a que su contenido es estático, plano y no invita a la interacción, no promueve el diálogo y no genera un círculo virtuoso donde se vaya incrementando la comunicación entre toda la comunidad de seguidores. Asimismo, aunque tiene una exposición de casos para velar por el respeto de la dignidad de la persona, por la humanidad y el bienestar de los migrantes, no logra hacer un real vínculo con sus seguidores y, a partir de ello, lograr mayores acciones o de mayor impacto social, económico, cultural o político.

\section{Conclusiones}

Como se observa, entre los principales hallazgos destacan la preponderancia del contenido relacionado con sus tres objetivos, así como la participación de los usuarios a partir de este. Sin embargo, falta la promoción de una verdadera colaboración que aproveche las ventajas de las redes sociales digitales, y mantener su uso como medio informativo y no abierto al diálogo o a la conformación de comunidad. Estos hallazgos permiten identificar el bajo impacto que tiene esta comunicación digital entre sus seguidores, lo que hace necesario proponer y definir 


\section{DISERTACIONES}

AVANCES

algunas pautas del contenido más relevante para el logro de los objetivos de la oım en una circunstancia tan apremiante como es la pandemia por el coronavirus SARS-CoV-2, con la ayuda de las herramientas de las redes sociodigitales. Entre los principales se encuentran:

1. Construir significados compartidos a partir del reflejo de situaciones reales más cercanas a la interacción que tienen los ciudadanos con los migrantes.

2. Definir acciones concretas que se puedan promover para fomentar la solidaridad ante los migrantes.

3. Crear espacios virtuales y físicos para la convivencia entre migrantes y ciudadanos del país receptor, a fin de generar vínculos reales que permitan su integración.

4. Dar a conocer la agenda de cooperación internacional que tiene la oı y los pequeños y grandes momentos de acuerdos y logros que se tienen, a partir de la realidad más cercana de los seguidores y, con ello, lograr su identificación.

5. Realizar periódicamente estudios que les permitan contar con información de primera mano para la toma de decisiones, sobre todo, en tiempo de pandemia por covid-19.

6. Establecer un programa de seguimiento local, regional y global a líderes de opinión y organismos cúpula integrados a sus objetivos, con quienes puedan establecer alianzas para informar a los ciudadanos sobre los aspectos más relevantes de migración.

7. Diseñar un esquema que permita la participación y escucha de los ciudadanos en la búsqueda de soluciones de manera que se integre cada vez más la comunidad alrededor de la oı con distintos alcances pero todos bajo el mismo fin: el respeto de la dignidad humana de los migrantes.

Si la oım emprende una estrategia de comunicación digital que no solo informe y promueva sus objetivos, sino que además busque el diálogo (conexión) para llegar a la construcción de comunidad (colaboración), entonces sus resultados serían cada vez más fuertes y su impacto sería más amplio. Esta tarea de potenciar el impacto de la oıм a través de su comunicación vía las redes sociales digitales es de cada uno de los tomadores de decisiones, pero también de cada uno de los ciudadanos del mundo que decidan involucrarse para interactuar, comprometerse, tomar acciones, resolver problemas; en suma, para convertirse en parte de la solución y no solo observadores pasivos del problema.

\section{Referencias}

1. Almansa-Martínez, A., \& Fernández-Torres, M. J. (2011). Estudio sobre la comunicación digital de las organizaciones sociales en España. Vivat Academia, 117, 337-252. https://www.redalyc.org/articulo. oa?id=525752959027

2. Arévalo-Martínez, R. I. (2019). Comunicación integral para las organizaciones: Liderazgo y creación de valor. Comunicación Social Ediciones y Publicaciones.

3. Arévalo-Martínez, R. I., \& Rebeil, M. (2017). Presencia, interacción y responsabilidad social organizacional en las redes sociales digitales de organizaciones privadas en Iberoamérica. En R. I. Arévalo-Martínez, R. I. y M. Rebeil (Coords.), Responsabilidad social en la comunicación digital organizacional (pp. 17-51). Tirant Humanidades-Universidad Anáhuac México. 


\section{DISERTACIONES}

AVANCES

Comunicación y controversias sociocientificas en salud y medio ambiente

ISSN: 1856-9536

Doi: https://doi.org/10.12804/revistas.urosario.edu.co/disertaciones/a.10389

Volumen 14, Número 2 / Julio-diciembre 2021

Versión PDF para imprimir desde

http://revistas.urosario.edu.co/index.php/disertaciones

4. Bardin, L. (1996). Análisis de contenido. Akal.

5. Calleja-Reina, M. A., Paniagua, F. J., \& Victoria, J. S. (2018). Herramientas digitales y comunicación de crisis: El papel de las redes sociales según la voz de los expertos. Estudios sobre el Mensaje Periodístico, 24(2), 1147-1167. http://dx.doi.org/10.5209/ESMP.62206

6. Capriotti, P., Zeler, I., \& Oliveira, A. (2019). Comunicación dialógica 2.0 en Facebook: Análisis de la interacción en las organizaciones de América Latina. Revista Latina de Comunicación Social, (74), 1094-1113. https://doi.org/10.4185/RLCS-2019-1373

7. Castles, S., \& Miller, M. (2004). La era de la migración: Movimientos internacionales de población en el mundo moderno. Porrúa.

8. Chávez-Ángeles, M., \& Sánchez-Medina, P. (2013). Las tecnologías de la información y comunicación (тіc) como recurso común: Coordinación, competencia y brecha digital en ocho municipios de Oaxaca. Gestión y Comunicación Política, 22, 137-170. http://www.scielo.org.mx/scielo.php?script=sci_arttext\&pid= S1405-10792013000400005\&lng=es\&tlng=es

9. Comisión Económica para América Latina y el Caribe (Cepal). (2020). Los efectos del covid-19: Una oportunidad para reafirmar la centralidad de los derechos humanos de las personas migrantes en el desarrollo sostenible. https://repositorio.cepal.org/bitstream/handle/11362/46353/4/S2000618_es.pdf

10. Del Pino, C., \& Galán, E. (2010). Internet y los nuevos consumidores: El nuevo modelo publicitario. Telos: Cuadernos de Comunicación e Innovación, (82), 55-64. https://telos.fundaciontelefonica.com/url-direct/ pdf-generator?tipoContenido=articuloTelos\&idContenido=2010020215530001\&idioma=es

11. Del Prado Flores, R. (2014). Ética y redes sociales. Tirant Humanidades e Investigaciones y Estudios Superiores.

12. Del Prado Flores, R. (2018). Ética de la comunicación. Gedisa-Universidad Anáhuac México.

13. FAO. (2020). Los trabajadores migrantes y la pandemia de covid-19. http://www.fao.org/3/ca8559es/ca8559Es.pdf

14. Fernández, M., Plano, M., \& Brras, A. (2017). Análisis de contenido y diseño de las publicaciones realizadas en la red social Facebook por organizaciones de la sociedad civil (osc) de la Ciudad de la Plata y zona de influencia [sesión de congreso]. 33॰ Congreso Nacional de ADENAG "Construyendo en Administración. Docencia y esencia", Concordia, Argentina. http://sedici.unlp.edu.ar/handle/10915/70326

15. García, J., \& Galvis, A. (2019). El concepto de solidaridad desde el pensamiento filosófico del derecho de Jesús González Amuchastegui. Vox Juris, 37(2), 211-223. https://www.aulavirtualusmp.pe/ojs/index.php/ vj/article/view/1618/pdf17

16. González-Bustamante, B. (2015). Evaluando Twitter como indicador de opinión pública: Una mirada al arribo de Bachelet a la presidencial chilena 2013. Revista saAP. Publicación de Ciencia Política de la Sociedad Argentina de Análisis Político, 9(1),119-141. https://www.redalyc.org/articulo.oa?id=387142733006

17. Gutiérrez, G., Sánchez, M., \& Galiano, A. (2018). Redes sociales como medio de promoción turística en los países iberoamericanos. Retos. Revista de Ciencias de la Administración y Economía, 15(8), 135-150. https://doi.org/10.17163/ret.n15.2018.09

18. Guzmán, A., del Moral, M., González, F., \& Gil, H. (2013). Impacto de Twitter en la comunicación y promoción institucional de las universidades. Pixel-Bit. Revista de Medios y Educación, (43), 139-153. https:// www.redalyc.org/articulo.oa?id=36828074011 


\section{DISERTACIONES}

AVANCES

19. Herrera, M., \& Arévalo-Martínez, R. I. (2014). Key leadership challenges and factors in Public Relations and Communications in Mexico. En B. Berger \& J. Meng (Comps.). Public relations leaders as sensemakers: A global study of leadership in public relations and communication management (pp. 262-277). Routledge.

20. Ju, B., \& Sandel, T. (2019). Adaptation of Mainland Chinese labour migrants in Macao. Journal of International and Intercultural Communication, 48(3), 257-273. https://doi.org/10.1080/17475759.2019.1611624

21. Kinefuchi, E. (2010). Finding home in migration: Montagnard refugees and post-migration identity. Journal of International and Intercultural Communication, 3(3), 228-248. https://doi.org/10.1080/17513057.20 10.487220

22. Krippendorff, K. (1990) Metodología del análisis de contenido: Teoría y práctica. Paidós.

23. Lara-Navarra, P., López-Borrull, A., Sánchez-Navarro, J., \& Yánez, P. (2018). Medición de la influencia de usuarios en redes sociales: Propuesta Social Engagement. El Profesional de la información, 27(4), 899-908. https://doi.org/10.3145/epi.2018.jul.18

24. Mayring, P. (2000). Qualitative content analysis. Forum Qualitative Social Research, 1(2). http://qualitativeresearch.net/fqs/fqs-e/2-00inhalt-e.htm

25. Monserrat-Gauchi, J., Quiles-Soler, M., \& Martínez-Sala, A. (2017). La participación ciudadana en la comunicación de las organizaciones: Análisis de las franquicias de salud-belleza, decoración y restauración. Prisma Social, 18, 540-560. https://dialnet.unirioja.es/servlet/articulo?codigo=6220248

26. Muñoz, D., Sebastián, A., \& Núñez, M. (2019). La cultura corporativa: Claves de la palanca para la verdadera transformación digital. Revista Prisma Social, (25), 439-463. https://revistaprismasocial.es/article/ view/2675

27. Naciones Unidas. (s. f.). Migración. https://www.un.org/es/sections/issues-depth/migration/index.html

28. Organización Internacional para las Migraciones (оıм). (2019a). Enunciado de misión. https://www.iom.int/ es/enunciado-de-mision

29. Organización Internacional para las Migraciones (омм). (2019b). Historia. https://www.iom.int/es/historia

30. Organización Internacional para las Migraciones (омм). (2019c). ¿Quién es un migrante? https://www.iom. int/es/quien-es-un-migrante

31. Organización Internacional para las Migraciones (омм). (2020). Instantáneas analíticas sobre la coviD-19: La desinformación sobre la migración y los migrantes. https://www.iom.int/sites/default/files/documents/ instantaneas_analiticas_covid-19_19_la_desinformacion_sobre_la_migracion_y_los_migrantes.pdf

32. Pécoud, A. (2018). ¿Una nueva 'gobernanza' de la migración?: Lo que dicen las organizaciones internacionales. Migración/Desarrollo, 16(30), 31-34. http://www.scielo.org.mx/pdf/myd/v16n30/1870-7599myd-16-30-31.pdf

33. Pérez, G. (1994). Investigación cualitativa: Retos e interrogantes. Tomo II: Técnicas de análisis de datos. La Muralla.

34. Rodríguez, B., Bao, L., \& Saltos, R. (2015). Estrategia de comunicación en redes sociales: Escenarios teórico prácticos para los medios de comunicación en Cuba. Razón y Palabra, (92), 1-40. https://www.redalyc. org/articulo.oa?id=199543036010 


\section{DISERTACIONES}

\section{AVANCES}

35. Sánchez, M., Correia, M., \& de Matos, N. (2018). Principales temas utilizados en la comunicación social de las ong de inmigración en España a través de la red social Facebook. Doxa Comunicación, (27), 213-232. https://doi.org/10.31921/doxacom.n27a10

36. Sánchez, M., \& Pinochet, G. (2017). El rol de las redes sociales virtuales en la difusión de información y conocimiento: estudio de casos. Universidad \& Empresa, 19(32), 107-135. https://www.redalyc.org/articulo. oa?id=187247578006

37. Sánchez-Hervás, D., \& Subiela-Hernández, B.-J. (2020). Organizaciones nativas responsables: La Rsc en la cultura de las startups digitales españolas. Revista Prisma Social, (29), 138-154. https://revistaprismasocial.es/article/view/3579

38. Unesco. (2020). Periodismo, libertad de prensa y covid-19. https://en.unesco.org/sites/default/files/ unesco_covid_brief_es.pdf 